\title{
VELOCIDADE DE SEMEADURA E PROFUNDIDADE DA SEMENTE NO SULCO AFETANDO A PRODUTIVIDADE DE GRÃOS DO ARROZ DE TERRAS ALTAS
}

\author{
José Geraldo da Silva, Adriano Stephan Nascente, Pedro Marques da Silveira
}

Embrapa Arroz e Feijão em Santo Antônio de Goiás, GO. E-mail: adriano.nascente@embrapa.br

\section{RESUMO}

A uniformidade da semeadura nas áreas agrícolas pode ser afetada por diversos fatores, tais como a velocidade de deslocamento do conjunto trator-semeadora e a profundidade de colocação da semente no sulco de plantio. Esses fatores podem afetar significativamente a produtividade de grãos das culturas. $O$ objetivo do trabalho foi o de quantificar o efeito da velocidade de semeadura e da profundidade de colocação da semente no sulco no estande de plantas, no índice de velocidade de emergência da plântula, nos componentes de produção e na produtividade de grãos do arroz de terras altas. O delineamento experimental foi em blocos ao acaso no esquema fatorial $3 \times 2$, com quatro repetições. Os tratamentos constaram da combinação de três velocidades de semeadura $\left(3,5\right.$ e $\left.7 \mathrm{~km} \mathrm{~h}^{-1}\right)$ com duas profundidades de colocação das sementes nos sulcos ( 3 e $6 \mathrm{~cm}$ ). A profundidade de semeadura teve efeito significativo sobre o índice de velocidade de emergência de plântulas e o estande de plantas de arroz, e não afetou o número de perfilhos, de panículas e de grãos por panícula, massa de 100 grãos e produtividade de grãos. A velocidade de semeadura não interferiu no índice de velocidade de emergência de plântulas, estande de plantas de arroz, número de perfilhos e de panículas e massa de 100 grãos. Por outro lado, afetou o número de grãos por panícula e a produtividade de grãos do arroz.

Palavras-chave: Oryza sativa; perfilhamento; espaçamento entre plantas; qualidade de semeadura; velocidade de emergência.

\section{SEEDER MACHINE VELOCITY AND SOWING DEEP AS AFFECTING UPLAND RICE GRAIN YIELD}

\begin{abstract}
The uniformity of sowing in the agricultural areas can be affected by several factors, such as the speed of the tractor-sowing set and the depth of placement of the seed in the sowing furrow. These factors can significantly affect the grain yield of crops. The objective of this work was to quantify the effect of sowing velocity and depth of seed placement on the furrow in plant stand, seedling emergence speed index, yield components and grain yield of upland rice. The experimental design was randomly blocks in factorial scheme $3 \times 2$, with four replicates. The treatments consisted of the combination of three sowing speeds $\left(3,5\right.$ and $\left.7 \mathrm{~km} \mathrm{~h}^{-1}\right)$ with two depths of seed placement in the sowing furrows $(3$ and $6 \mathrm{~cm}$ ). Sowing depth significantly affected the seedling emergence speed index and plant stand of rice, without affecting the number of tillers, number of panicles, number of grains per panicle, mass of 1000 grains and grain yield. Sowing speed did not affect seedling emergence speed index, plant stand, number of tillers, number of panicles and mass of 1000 grains. On the other hand, it affected the number of grains per panicle and the grain yield of rice.
\end{abstract}

Keywords: Oryza sativa; tillering; plant spacing; sowing quality; emergence speed.

\section{INTRODUÇÃO}

O arroz é uma cultura de grande importância econômica e social em muitos países, sendo a base da alimentação de metade da população mundial (FAOSTAT, 2017). A cultura pode ser cultivada em dois ecossistemas, o de 
terras baixas em várzea úmida com ou sem irrigação e o de terras altas, com irrigação suplementar ou dependente da água da chuva. No mundo, $76 \%$ do arroz é cultivado em várzea úmida com irrigação, $20 \%$ em várzea dependente de chuva e 4\% em condições de terras altas (MACLEAN et al., 2013). Entretanto, devido à redução da disponibilidade de água para irrigação pelo aumento do consumo humano e industrial (PRASAD, 2011), o cultivo do arroz no ambiente terras altas vem crescendo em importância mundial (NASCENTE et al., 2017).

Dessa forma, necessário se faz desenvolver tecnologias para proporcionar incrementos na produtividade do arroz de terras altas para torná-lo ainda mais atrativo aos agricultores. Nesse sentido, o processo de semeadura é uma das ações que requerem mais cuidados (ALMEIDA et al., 2010; MACEDO et al., 2016) e um dos mais importantes no sistema produtivo, uma vez que a etapa da semeadura bem realizada tende a proporcionar plantas mais uniformes, com reflexos positivos na produtividade das culturas (FURLANI et al., 2008; WEIRICH NETO et al., 2015).

No processo de semeadura o conjunto trator-semeadora deve estar bem ajustado em relação às condições edáficas da propriedade, como o sistema convencional (uma aração e duas gradagens), SPD com pouca palha, SPD com muita palha, solos compactados, solos mais arenosos ou mais argilosos. Assim, a regulagem pode variar em diferentes situações do solo, e se o equipamento for mal regulado, pode levar a problemas na profundidade da semente no sulco e na emergência das plântulas (RODRIGUES et al., 2011; MACEDO et al., 2016). Portanto, o mecanismo de corte da semeadora não pode ser limitado a uma única configuração e deve possibilitar vários ajustes de profundidade dependendo das características do solo que se vai trabalhar.

A operação em subsuperfície usando haste sulcadora para abrir o sulco de semeadura influencia na demanda de energia e no aumento da velocidade do trator, exigindo maior poder de tração para trabalhar em profundidades maiores (CEPIK et al., 2010). Conte et al. (2009) estudando a abertura dos sulcos de semeadura nas profundidades de 0,06 $\mathrm{m}$ e 0,12 $\mathrm{m}$, também observaram maior exigência de potência quando as hastes foram utilizadas na maior profundidade.
Entretanto, esses autores afirmaram que houve efeito benéfico com relação ao estresse hídrico causado pelo aumento do crescimento radicular pela quebra de camadas compactadas, o que contribuiu para a manutenção da produtividade da soja em condições de escassez de água.

No processo de semeadura é importante a avaliação da velocidade do trator, pois a uniformidade da distribuição da semente está diretamente relacionada à velocidade de deslocamento (TROGELLO et al., 2013b) e pode influenciar a abertura e o fechamento dos sulcos de semeadura e a profundidade de deposição das sementes (TROGELLO et al., 2013a). Dessa forma, constata-se que, mesmo utilizando-se densidades recomendadas, o processo de semeadura pode proporcionar distribuição desuniforme da semente na linha, além da sua colocação em profundidades maiores do que o planejado. Com isso, podem ocorrer plantas muito próximas umas das outras na linha, que irão competir entre si, inibindo o seu desenvolvimento, e com maiores comprimentos do hipocótilo, com reflexos negativos na produtividade da cultura (MONDO et al., 2012). Em qualquer cultivo, a profundidade de semeadura e a distribuição das sementes na linha devem ser adequadas para garantir a germinação das sementes, a emergência e o desenvolvimento das plântulas (RODRIGUES et al., 2011; DERRÉ et al., 2016). A profundidade de colocação da semente é específica para cada espécie e quando adequada, propicia germinação e emergência de plântulas uniformes (TROGELLO et al., 2013a). Segundo Cortez et al. (2006), considera-se como aceitáveis todos os espaçamentos entre plantas de 0,5 a 1,5 vez o espaçamento médio (EM) esperado. Os valores obtidos fora desse limite são considerados falhos (acima de 1,5 vez o EM) ou múltiplos (abaixo de 0,5 vez o EM).

Assim, constata-se que o processo de semeadura é uma atividade importante na implantação das culturas, e deve ser realizado com cuidado para se obter populações adequadas, na profundidade recomendada e plantas espaçadas equitativamente. Do contrário, todo o investimento realizado não irá se traduzir em ganhos de produtividade. Entretanto, ao contrário da soja e do milho, praticamente não existem estudos sobre o efeito da distribuição longitudinal, da profundidade de semeadura e da velocidade do 
trator no processo de semeadura do arroz de terras altas. Com isso surge a necessidade de investigá-los para constatar o real efeito desses fatores na produtividade final da cultura. Diante do exposto, o objetivo do trabalho foi quantificar o efeito da velocidade de semeadura e da profundidade de deposição das sementes no estande de plantas, índice de velocidade de emergência de plântulas, componentes de produção e produtividade de grãos do arroz de terras altas cultivado em região do Cerrado.

\section{MATERIAL E MÉTODOS}

O experimento foi conduzido na safra de verão 2016/17, na Fazenda Capivara da Embrapa Arroz e Feijão, localizada no município de Santo Antônio de Goiás, GO, a 1628'00" S e 4917'00" $W$, e $823 \mathrm{~m}$ de altitude. 0 clima da região é tropical de savana, sendo considerado do tipo Aw segundo a classificação de Köppen. Há duas estações bem definidas, normalmente seco de maio a setembro (outono/inverno) e chuvoso de outubro a abril (primavera / verão), a precipitação pluvial média anual está entre 1.500 a $1.700 \mathrm{~mm}$. A temperatura média anual é de $22,7^{\circ} \mathrm{C}$, variando anualmente de
$14,2{ }^{\circ} \mathrm{C}$ a $34,8{ }^{\circ} \mathrm{C}$. Adicionalmente durante a condução do experimento os dados de temperatura e precipitação pluvial foram monitorados (Figura 1).

O solo foi classificado como Latossolo Vermelho ácrico (Embrapa, 2006). Antes da instalação do experimento, em novembro de 2016, foram realizadas análises químicas, na profundidade de 0-0,05, 0,05-0,10 e 0,10-0,20 m para caracterização da área experimental (Tabela 1). As análises químicas foram realizadas de acordo com a metodologia proposta por Donagema et al. (2011). A área experimental vem sendo cultivada sob sistema plantio direto em rotação com milho e soja no verão.

$O$ delineamento experimental foi 0 de blocos ao acaso no esquema fatorial $3 \times 2$, com quatro repetições. Os tratamentos constaram da combinação de três velocidades de semeadura $(3,5$ e $7 \mathrm{~km} \mathrm{~h}^{-1}$ ) com duas profundidades de colocação das sementes nos sulcos ( 3 e $6 \mathrm{~cm}$ ). Cada parcela foi composta por cinco linhas de arroz com 5 metros de comprimento. A área útil foi composta pelas três linhas centrais, desprezando-se $0,50 \mathrm{~cm}$ das extremidades de cada linha.



Figura 1. Temperatura média e precipitação pluvial durante a condução do experimento. 
Tabela 1. Atributos químicos do solo da área antes da instalação do experimento. Santo Antônio de Goiás, safra 2016/17.

\begin{tabular}{|c|c|c|c|c|c|c|c|}
\hline Profundidade & $\mathrm{Ca}$ & $\mathrm{Mg}$ & $\mathrm{Al}$ & $\mathrm{H}+\mathrm{Al}$ & $P$ & $K$ & $\mathrm{pH}\left(\mathrm{H}_{2} \mathrm{O}\right)$ \\
\hline (m) & ------- & $---m m$ & 3 & ---- & ------m & -3---- & \\
\hline $0-0,05$ & 17,4 & 10,5 & 1,0 & 38,0 & 24,9 & 134 & 4,8 \\
\hline $0,05-0,10$ & 11,3 & 6,8 & 2,0 & 37,0 & 26,8 & 86 & 4,6 \\
\hline $0,10-0,20$ & 7,1 & 4,6 & 4,0 & 35,0 & 20,2 & 42 & 4,4 \\
\hline Profundidade & $\mathrm{MO}^{1}$ & & & $\mathrm{Cu}$ & & & $\mathrm{Mn}$ \\
\hline (m) & $\mathrm{g} \mathrm{kg}^{-1}$ & \multicolumn{6}{|c|}{---------------------'mg dm³ } \\
\hline $0-0,05$ & 36,34 & \multicolumn{2}{|c|}{3,9} & 1,9 & \multicolumn{2}{|c|}{31,5} & 8,8 \\
\hline $0,05-0,10$ & 30,38 & \multicolumn{2}{|c|}{3,3} & 1,6 & \multicolumn{2}{|c|}{30,5} & 7,3 \\
\hline $0,10-0,20$ & 27,81 & \multicolumn{2}{|c|}{2,3} & 1,3 & \multicolumn{2}{|c|}{29,7} & 5,2 \\
\hline
\end{tabular}

${ }^{1} \mathrm{MO}$ - matéria orgânica

A semeadura do arroz, cultivar BRS $501 \mathrm{CL}$, foi realizada mecanicamente em 13/12/2016, no espaçamento fixo de $0,45 \mathrm{~m}$ entrelinhas e a semeadora regulada para se obter 80 plantas $\mathrm{m}^{-1}$. Para isso, utilizou-se de semeadora adubadora de cinco linhas de semeadura, tracionada pelo trator pela barra de tração, e a semeadora provida de rotor acanalado para a distribuição das sementes e sulcador de discos duplos desencontrados. Foi realizada a adubação por área, com base na análise do solo (SOUSA; LOBATO, 2004), na quantidade de $300 \mathrm{~kg} \mathrm{ha}^{-1}$ do formulado 5-30-15. O controle de insetos-pragas, doenças e plantas daninhas foi realizado de acordo com as necessidades da cultura (SANTOS et al., 2006). No estádio fenológico de início de perfilhamento (aproximadamente 20 dias após a emergência) foi realizada a adubação de cobertura com $60 \mathrm{~kg} \mathrm{ha}^{-1}$ de $\mathrm{N}$ na forma de ureia. A colheita foi realizada dia 07 de abril de 2017.

Foram realizadas as seguintes avaliações:

Índice de velocidade de emergência de plântulas, calculado pela fórmula:

$\mathrm{IVE}=(\mathrm{N} 1 / \mathrm{D} 1)+(\mathrm{N} 2 / \mathrm{D} 2)+\ldots \ldots .+(\mathrm{Nn} / \mathrm{Dn})$,

Sendo:

IVE = índice de velocidade de emergência de plântulas;

N1= Número de plântulas na primeira contagem;

N2= Número de plântulas entre a primeira e a segunda contagem;

$\mathrm{Nn}=$ Número de plântulas entre a penúltima e a última contagem

D1= Número de dias da semeadura até a primeira contagem ( 7 dias, realizada em 20/12/2016);
D2= Número de dias da semeadura até a segunda contagem (8 dias, realizada em 21/12/2016);

$\mathrm{Dn}=$ Número de dias da semeadura até o último dia de contagem (14 dias, realizada em 27/12/2016).

Estande final de plantas, definido pela contagem do número de plantas por metro, emergidas no dia 27/12/2016, 14 dias após a semeadura. Foi feita a colheita do arroz após a maturação fisiológica, manualmente na área útil de cada parcela. As plantas foram trilhadas e os grãos pesados corrigindo-se os valores para $13 \%$ de umidade. Para avaliar os componentes da produção foram coletadas 10 panículas ao acaso na área útil de cada parcela e levadas ao laboratório para avaliação (contagem de número de grãos por panícula e massa de grãos). Coletaram-se também as plantas em 2 metros na área útil de cada parcela para a contagem do número de perfilhos e panículas. Todos os grãos colhidos na área útil da parcela foram pesados e calculada a produtividade em kg ha-1.

Os dados foram submetidos à análise de variância e quando necessário realizado o teste comparativo de médias Tukey para $p<0,05$. Foi utilizado o programa estatístico SAS.

\section{RESULTADOS E DISCUSSÃO}

A análise estatística revelou que a profundidade de semeadura afetou significativamente o estande de plantas e o índice de velocidade de emergência de plântulas (Tabela 2). Assim, profundidade de semeadura de $3 \mathrm{~cm}$ proporcionou maiores valores nas duas variáveis do que a profundidade de $6 \mathrm{~cm}$. De acordo com 
Trogello et al. (2008) profundidades inadequadas de semeadura podem afetar significativamente a emergência de plântulas e o estande de plantas. 0 menor estande de plantas encontrado na profundidade de $6 \mathrm{~cm}$, pode estar associado a problemas de vigor de sementes, que em maiores profundidades necessitaria de mais reservas de nutrientes parar romper a maior camada de solo quando comparada com a profundidade de $3 \mathrm{~cm}$, retardando, assim, o processo de emergência e reduzindo a percentagem de germinação das plântulas. Fornasieri Filho (1992) destaca que semeaduras a maiores profundidades podem retardar e até impedir a emergência de plântulas, devido à falta de reservas de nutrientes na semente ou pela incapacidade de se alongarem até alcançar a luz. Da mesma forma, Sordi (2000) e Santos et al. (2006) trabalhando com três profundidades de semeadura na cultura do feijãocomum e soja, respectivamente, relataram que o índice de emergência das plântulas foi mais rápido nas menores profundidades de semeadura.

Tabela 2. Estande de plantas (estande) e índice de velocidade de emergência de plântulas (IVE) do arroz, cultivar BRS 501 CL, em função da velocidade de semeadura e profundidade de deposição da semente no sulco de semeadura.

\begin{tabular}{ccc}
\hline Fatores & Estande & IVE \\
\hline Profundidade & número & $\% 2 \mathrm{a}$ \\
3 & $54 \mathrm{a}^{*}$ & $45 \mathrm{~b}$ \\
6 & $42 \mathrm{~b}$ & \\
Velocidade & & $48 \mathrm{a}$ \\
3 & $47 \mathrm{a}$ & $47 \mathrm{a}$ \\
5 & $44 \mathrm{a}$ & $50 \mathrm{a}$ \\
7 & $53 \mathrm{a}$ & 0,0034 \\
\hline Fatores & ANAVA (Probabilidade do teste F) \\
\hline Profundidade (P) & 0,0001 & 0,4806 \\
Velocidade (V) & 0,5594 & 0,0701 \\
P x V & 0,0592 &
\end{tabular}

*Médias seguidas pela mesma letra, não diferem entre si pelo teste Tukey para $p<0,05$.

Por outro lado, a velocidade de semeadura não influenciou o estande de plantas e nem o índice de velocidade de emergência de plântulas, IVE (Tabela 2). Silva (2000) também relatou que o estande de plantas não foi influenciado pela velocidade de deslocamento na implantação de culturas de milho e soja. Mahl et al. (2004) observaram que a variação da velocidade não interferiu na população inicial de plantas de milho. Assim, constata-se que nas velocidades de 3, 5 e 7 $\mathrm{km} \mathrm{h}^{-1}$, a distribuição de sementes por área não foi afetada, proporcionando valores semelhantes nas variáveis estande de plantas e IVE.

A profundidade de semeadura não afetou as variáveis número de perfilhos, número de panículas, número de grãos por panícula, massa de 1000 grãos e produtividade de grãos do arroz de terras altas (Tabela 3). Isso pode ser devido ao fato de que mesmo tendo afetado o estande de plantas, as plantas de arroz têm a capacidade de "compensar" a falta de plantas, aumentando o perfilhamento (SANTOS et al., 2006). Essa capacidade de perfilhamento faz com que o arroz tenha resposta elástica à densidade de plantas, podendo compensar baixas densidades pela maior emissão de perfilhos (REUNIÃO..., 2016). Corroborando essa informação, o número de perfilhos por metro foi praticamente igual nas duas profundidades. A produtividade de grãos de arroz é determinada por três componentes de produção: número de panículas por área, número de grãos por panícula e massa de 1000 grãos (YOSHIDA, 1981; LACERDA; NASCENTE, 2016). Como esses fatores foram semelhantes, era de se esperar produtividades similares, como obtido. 
Tabela 3. Número de perfilhos (Perf), número de panículas (Pan), número de grãos por panícula (NGP), massa de 1000 grãos (M1000) e produtividade de grãos (Prod) do arroz cultivar BRS 501 CL em função da velocidade de semeadura e profundidade de deposição da semente no sulco de semeadura.

\begin{tabular}{|c|c|c|c|c|c|}
\hline Fatores & Perf & Pan & NGP & M1000 & Prod \\
\hline Profundidade & $\mathrm{n} \mathrm{m}^{-1}$ & $\mathrm{n} \mathrm{m}^{-1}$ & $\mathrm{n}$ & g & $\mathrm{kg} \mathrm{ha}^{-1}$ \\
\hline 3 & $121 a^{*}$ & $117 \mathrm{a}$ & $137 \mathrm{a}$ & $24 a$ & $4.184 \mathrm{a}$ \\
\hline 6 & $120 \mathrm{a}$ & $116 \mathrm{a}$ & $138 \mathrm{a}$ & $24 a$ & $4.237 \mathrm{a}$ \\
\hline \multicolumn{6}{|l|}{ Velocidade } \\
\hline 3 & $123 \mathrm{a}$ & 119 a & 149 a & $24 a$ & $4.711 \mathrm{a}$ \\
\hline 5 & $112 \mathrm{a}$ & 109 a & $140 \mathrm{ab}$ & $24 a$ & $4.000 \mathrm{~b}$ \\
\hline 7 & $127 \mathrm{a}$ & $122 \mathrm{a}$ & $123 \mathrm{~b}$ & $23 \mathrm{a}$ & $3.920 \mathrm{~b}$ \\
\hline Fatores & \multicolumn{5}{|c|}{ ANAVA (Probabilidade do teste F) } \\
\hline Profundidade $(\mathrm{P})$ & 0,1412 & 0,1659 & 0,5600 & 0,2310 & 0,4819 \\
\hline Velocidade (V) & 0,6324 & 0,7873 & 0,0440 & 0,2257 & $<0,001$ \\
\hline$P \times V$ & 0,1752 & 0,1823 & 0,0580 & 0,2157 & 0,0502 \\
\hline
\end{tabular}

*Médias seguidas da mesma letra, não diferem entre si pelo teste Tukey para $p<0,005$.

A velocidade de semeadura não afetou o número de perfilhos, número de panículas e massa de 1000 grãos (Tabela 3). Por outro lado, afetou significativamente o número de grãos por panícula e a produtividade de grãos. Dessa forma, a menor velocidade de semeadura proporcionou maior número de grãos por panícula e também produtividade de grãos. As maiores velocidades de semeadura podem ter proporcionado a deposição mais superficial das sementes. Garcia et al. (2006) relatam sementes expostas com o aumento da velocidade de deslocamento da semeadora. Trojello et al. (2013a) relataram que a velocidade de deslocamento do conjunto trator-semeadora afeta diretamente na obtenção da profundidade desejada.

Nesse sentido, a área do presente experimento apresentou falta de chuvas entre os dias 15 e 22 de fevereiro (Figura 1). Esse período coincidiu com a fase do florescimento da cultura que é quando se define a fertilidade das espiguetas e o número de grãos por panícula (SANTOS et al., 2006; REUNIÃO..., 2016). Assim, é provável que a velocidade mais lenta $\left(3 \mathrm{~km} \mathrm{~h}^{-1}\right)$ tenha proporcionado a deposição das sementes em maior profundidade e as plantas desenvolveram melhor o sistema radicular e sentiram menos esse período de estiagem do que as plantas originadas das sementes depositadas mais superficialmente com as maiores velocidades de deslocamento $(5$ e $7 \mathrm{~km}$ $\mathrm{h}^{-1}$ ). De acordo com Heinemann e Stone (2009) mesmo semeando o arroz na época das águas, existe a probabilidade de ocorrência de veranicos, períodos nos quais não há precipitação pluvial ou a precipitação pluvial é menor que a demanda, podendo expor a cultura a um período de estresse hídrico. Os efeitos negativos desse estresse podem ser intensificados se houver restrição ao crescimento radicular, sendo que uma das fases mais críticas é o florescimento (HEINEMANN, 2010).

Com base nos resultados obtidos pode-se inferir que profundidade de semeadura de $6 \mathrm{~cm}$, causa redução na emergência de plântulas e no estande inicial de plantas de arroz. Entretanto a planta de arroz compensa essa quantidade menor de plantas com maior perfilhamento, o que proporciona produtividades semelhantes. A velocidade de semeadura não afeta o número de perfilhos, número de panículas e massa de 100 grãos, entretanto, é provável que com menores velocidades, as sementes sejam posicionadas na profundidade planejada e com isso as plantas apresentem maior enraizamento em profundidade e melhor desenvolvimento nessas condições, o que é relevante caso ocorra períodos de restrição hídrica.

\section{CONCLUSÕES}

A profundidade de semeadura não afetou significativamente o número de perfilhos, número de panículas, número de grãos por panícula, massa de 100 grãos e produtividade de grãos, mas na profundidade de $3 \mathrm{~cm}$ obteve-se maior índice de 
velocidade de emergência de plantas e estande de plantas de arroz;

A velocidade de semeadura não afetou o índice de velocidade de emergência de plântulas, estande de plantas, número de perfilhos, número de panículas e massa de 100 grãos, mas na velocidade de $3 \mathrm{~km} \mathrm{~h}^{-1}$ obteve-se maior o número

\section{REFERÊNCIAS}

ALMEIDA, R.A.S.; SILVA, C.A.T.; SILVA, S.L. Desempenho energético de um conjunto tratorsemeadora em função do escalonamento de marchas e rotações do motor. Agrarian, v. 3, n.7, p. 63-70, 2010.

CEPIK, C.T.C.; TREIN, C.R.; LEVIEN, R.; CONTE, O. Força de tração e mobilização do solo por hastes sulcadoras de semadoras-adubadoras. Revista Brasileira de Engenharia Agrícola e Ambiental, v.14, n.5, p.561-566, 2010. https://doi.org/10.1590/S1415$\underline{43662010000500015}$

CONTE, O.; LEVIEN, R.; TREIN, C.R.; XAVIER, A.A.P.; DEBIASI, H. Demanda de tração, mobilização de solo na linha de semeadura e rendimento da soja, em plantio direto. Pesquisa Agropecuária Brasileira, v.44, n.10, p.1.254-1.261, 2009.

CORTEZ, J.W.; FURLANI, C.E.A.; SILVA, R.P.; LOPES, A. Distribuição longitudinal de sementes de soja e características físicas do solo no plantio direto. Engenharia Agrícola, v.26, n.2, p.502-510, 2006. https://doi.org/10.1590/s0100$\underline{69162006000200019}$

DERRÉ, L.O.; ABRANTES, F.L.; ARANDA, E.A.; FEITOSA, E.M.; CUSTÓDIO, C.C. Embebição e profundidade de semeadura de sementes não revestidas e revestidas de forrageiras. Colloquium Agrariae, v.12, n.2, p.19-31, 2016. https://doi.org/10.5747/ca.2016.v12.n2.a136

DONAGEMA, G.K.; CAMPOS, D.V.B.; CALDERANO, S.B.; TEIXEIRA, W.G. Manual de métodos de análise de solo. 2. ed. Rio de Janeiro: Embrapa Solos, 2011. de grãos por panícula e produtividade de grãos do arroz.

\section{AGRADECIMENTOS}

À Embrapa pelo financiamento da pesquisa e ao CNPq pela bolsa de produtividade em pesquisa para o segundo e terceiro autores.

FAOSTAT. Production: Crops. 2017. Disponível em: <www.faostat.fao.org>. Acesso em: 29 mar. 2017.

FORNASIERI FILHO, D. A cultura do milho. Jaboticabal: Funep, 1992.

FURLANI, C.E.A.; SILVA, R.P.; CARVALHO FILHO, A.; CORTEZ, J.W.; GROTTA, D.C.C. Semeadoraadubadora: exigências em função do preparo do solo, da pressão de inflação do pneu e da velocidade. Revista Brasileira de Ciência do Solo, v.32, n.1, p.345-352, 2008. https://doi.org/10.1590/s0100$\underline{06832008000100032}$

GARCIA, L.C.; JASPER, R.; JASPER, M.; FORNARI, A.J.; $B L U M$, J. Influência da velocidade de deslocamento na semeadura do milho. Engenharia Agrícola, v.26, n.2, p.520-527, 2006. https://doi.org/10.1590/S0100$\underline{69162006000200021}$

HEINEMANN, A.B. Caracterização dos padrões de estresse hídrico para a cultura do arroz (ciclo curto e médio) no estado de Goiás e suas consequências para o melhoramento genético. Ciência e Agrotecnologia, v. 34, n.1, p.29-36, 2010. https://doi.org/10.1590/S1413-

$\underline{70542010000100003}$

HEINEMANN, A.B.; STONE, L.F. Efeito da deficiência hídrica no desenvolvimento e rendimento de quatro cultivares de arroz de terras altas. Pesquisa Agropecuária Tropical, v. 39, n.2, p.134-139, 2009.

LACERDA, M.C.; NASCENTE, A.S. Effects of row spacing and nitrogen topdressing fertilization on the yield of upland rice in a no-tillage system. Acta Scientiarum. Agronomy, v. 38, n.4, p. 493-502, 
2016.

https://doi.org/10.4025/actasciagron.v38i4.30855

MACEDO, D.X.S.; NICOLAU, F.E.A.; NASCIMENTO, H.C.F.; COSTA, E.; CHIODEROLI, C.A.; LOUREIRO, D.R. Operational performance of a tractor-seeder according to the velocity and working depth. Revista Brasileira de Engenharia Agrícola e Ambiental. v.20, n.3, p.280-285, 2016. https://doi.org/10.1590/1807-

1929/agriambi.v20n3p280-285

MACLEAN, J.L.; DAWE, D.C.; HARDY, B.; HETTEL, G.P. Rice Almanac: Source book for one of the most important economic activity on Earth 4. ed. Philippines: IRRI, 2013.

MAHL, D.; GAMERO, C.A.; BENEZ, S.H.; FURLANI, C.E.A.; SILVA, A.R.B. Demanda energética e eficiência da distribuição de sementes de milho sob variação de velocidade e condição de solo. Engenharia Agrícola, v.24, n.1, p.150-157, 2004. https://doi.org/10.1590/s0100-

$\underline{69162004000100017}$

MONDO, V.H.V.; CICERO, S.M.; DOURADO-NETO, D.; PUPIM, T.L.; DIAS, M.A.N. Vigor de sementes e desempenho de plantas de milho. Revista Brasileira de Sementes, v. 34, n.1 p.143-155, 2012. https://doi.org/10.1590/S0101-

$\underline{31222012000100018}$

NASCENTE, A.S.; FILIPPI, M.C.C.; LANNA, A.C.; SOUZA, A.C.A.; LOBO, V.L.S; SILVA, G.B. Biomass, gas exchange, and nutrient contents in upland rice plants affected by application forms of microorganism growth promoters. Chemical and Biological Environmental Monitoring, v. 24, n.3, p. 2.9562.965, 2017.

PRASAD, R. Aerobic rice systems. In: SPARKS, D.L. Advances in agronomy, v.111, p.207-236, 2011. https://doi.org/10.1016/B978-0-12-3876898.00003-5

REUNIÃO TÉCNICA DA CULTURA DO ARROZ IRRIGADO. Arroz irrigado: recomendações técnicas da pesquisa para o Sul do Brasil. Pelotas: SOSBAI, 2016.
RODRIGUES, S.; SILVA, A.P.; GIAROLA, N.F.B.; ROSA, J.A. Permeabilidade ao ar em Latossolo Vermelho sob diferentes sistemas de manejo. Revista Brasileira de Ciência do Solo, v. 35, n.1, p.105-114, 2011. https://doi.org/10.1590/S0100-

$\underline{06832011000100010}$

SANTOS, A.B.; STONE, L.F.; VIEIRA, N.R.A. A cultura do arroz no Brasil. 2. ed. Santo Antônio de Goiás: Embrapa Arroz e Feijão, 2006.

SILVA, S.L. Avaliação de semeadoras para plantio direto: demanda energética, distribuição longitudinal e profundidade de deposição de sementes em diferentes velocidades de deslocamento. 2000. 123 f. Tese (Doutorado em Energia na Agricultura) - Faculdade de Ciências Agronômicas, Universidade Estadual Paulista, Botucatu, 2000.

SORDI, F. Efeito da profundidade de semeadura e compactação do solo sobre a semente na cultura do feijoeiro (Phaseolus vulgaris). 2000. $50 \mathrm{f}$. Monografia (Trabalho de Graduação em Agronomia) - Faculdade de Ciências Agrárias e Veterinárias, Universidade Estadual Paulista, Jaboticabal, 2000.

SOUSA, D.M.G.; LOBATO, E. Cerrado: correção do solo e adubação. 2. ed. Brasília: Embrapa, 2004.

TROGELLO, E.; MODOLO, A.J.; SCASI, M.; DALLACORT, R. Manejos de cobertura, mecanismos sulcadores e velocidades de operação sobre a semeadura direta da cultura do milho. Bragantia, v.72, n.1, p.101-109, 2013a. https://doi.org/10.1590/S0006$\underline{87052013005000016}$

TROGELLO, E.; MODOLO, A.J.; SCASI, M.; SILVA, L.C.; ADAMI, P.F.; DALLACORT, R. Manejos de cobertura vegetal e velocidades de operação em condições de semeadura e produtividade de milho. Revista Brasileira de Engenharia Agrícola e Ambiental, v.17, n.7, p.796-802, 2013b. https://doi.org/10.1590/S1415$\underline{43662013000700015}$

TROGELLO, E.; MODOLO, A.J.; NUNES, A.L.; DAMBROS, M.P.; PORTES, E.S. Efeito de diferentes 
profundidades de semeadura e cargas aplicadas pela roda compactadora sobre a população de plantas e produtividade da cultura do feijão. Synergismus scyentifica, v. 3, n. 4, p. 1-3, 2008.

WEIRICH NETO, P.H.; FORNARI, A.J.; JUSTINO, A.; GARCIA, L.C. Qualidade na semeadura do milho. Engenharia Agrícola, v.35, n.1, p.171-179, 2015. https://doi.org/10.1590/1809-4430-

Eng.Agric.v35n1p171-179/2015
YOSHIDA, S. Fundamentals of rice crop science. LoS Baños, Laguna: IRRI, 1981.

Recebido para publicação em 09/05/2017

Revisado em 03/07/2017

Aceito em 04/07/2017 